\title{
Fraction of exhaled nitric oxide measurements in the diagnoses of asthma in elderly patients
}

\author{
This article was published in the following Dove Press journal: \\ Clinical Interventions in Aging \\ 12 May 2016 \\ Number of times this article has been viewed
}

\author{
Antonio Carlos Maneira \\ Godinho Netto ${ }^{1,2}$ \\ Túlio Gonçalves dos Reis ${ }^{1,2}$ \\ Cássia Franco Matheus ${ }^{1,2}$ \\ Beatriz Julião Vieira \\ Aarestrup $^{3,4}$ \\ Fernando Monteiro \\ Aarestrup ${ }^{1,2,4}$ \\ 'School of Medical and Health \\ Sciences - SUPREMA, ${ }^{2}$ Maternity \\ Hospital Terezinha de Jesus, \\ ${ }_{3}^{3}$ Morphology Department, Federal \\ University of Juiz de Fora, Institute \\ of Biological Sciences, ${ }^{4}$ Laboratory of \\ Immunopathology and Experimental \\ Pathology, Federal University of Juiz \\ de Fora, Reproductive Biology Center \\ (CBR), Juiz de Fora, Brazil
}

Correspondence: Fernando Monteiro Aarestrup

Universidade Federal de Juiz de Fora (UFJF) - Centro de Biologia da Reprodução (CBR), Rua José Lourenço Kelmer, S/n - Martelos, Juiz de Fora, Minas Gerais 36036-330, Brazil

Tel +55 3288120350

Email fmaarestrup@hotmail.com
Objective: To assess the value of fraction of exhaled nitric oxide (FeNO) measurements in the diagnosis of asthma in elderly patients.

Methods: The clinical symptoms of 202 elderly patients were assessed with the asthma module of the International Study of Asthma and Allergies in Childhood test, which had been modified for the elderly patients, and the diagnostic routine for chronic obstructive pulmonary disease (COPD), which was based on the Global initiative for chronic Obstructive Lung Disease criteria. Of the 202 patients assessed, 43 were subjected to pulmonary function evaluations (spirometry) and FeNO measurements.

Results: Of the 202 elderly patients, 34 had asthma (23 definite and eleven probable), 20 met COPD criteria, 13 presented with an overlap of asthma and COPD, and 135 did not fit the criteria for obstructive pulmonary disease. Among the 43 elderly patients who were subjected to FeNO measurements, ten showed altered results $(23.2 \%)$ and 33 had normal results $(76.7 \%)$. The average value of FeNO in patients with definite and probable asthma undergoing this procedure was 29.2 parts per billion whereas that in nonasthmatic patients was 17.5 parts per billion $(P=0.0002)$.

Conclusion: We show a clear relationship between FeNO levels and asthma symptoms and previous asthma diagnoses in elderly patients.

Keywords: asthma, chronic obstructive pulmonary disease, elderly patients, nitric oxide

\section{Introduction}

Diagnosing asthma can be difficult in elderly patients because these patients often exhibit atypical symptoms and have altered perceptions of their symptoms. In addition, a number of comorbidities, such as chronic obstructive pulmonary disease (COPD), congestive heart failure, and gastroesophageal reflex disease, share symptoms with asthma and occur more frequently with aging. Spirometric alterations have also been shown to be associated with aging. ${ }^{1-7}$

Spirometry, which is the basis for COPD diagnoses, has been shown to be effective for identifying patients with severe asthma. ${ }^{1,2}$ In mild and moderate asthma cases, the diagnosis may be inconclusive and require a bronchial challenge test, which is a time-consuming procedure that must be done in specialized centers and that imposes a risk of bronchospasms. ${ }^{6}$

In this context, several previous studies have demonstrated that measurement of the fraction of exhaled nitric oxide (FeNO) can be used to monitor the inflammatory responses of asthmatic patients after the use of inhaled corticosteroids. Thus, these FeNO measurements provide doctors with immediate and noninvasively obtained evidence for determining necessary changes in the dosage of this drug. ${ }^{8-11}$

Nitric oxide (NO) is produced endogenously in various cell types present in the respiratory tract, particularly in the epithelial cells, vascular endothelium, and inflammatory 
cells (macrophages, eosinophils, and neutrophils). The transcription of the enzymatic isoform with a greater impact on NO production, inducible NO synthase, is regulated by proinflammatory cytokines from macrophages and epithelial cells in the late phase of the inflammatory response. An increase in NO production causes an increase in the number of T helper (Th) 2 cells, which promotes the process of eosinophilic inflammation in asthmatic patients. ${ }^{11}$ A study assessed the diagnostic use of FeNO measurement in 71 patients with chronic cough, and using FeNO measurements with a cutoff value of 38.8 parts per billion ( $\mathrm{ppb}$ ), allowed diagnosis of asthma with a sensitivity of $79.2 \%$ and a specificity of $91.3 \%$, which was superior to spirometry and bronchial challenge testing. ${ }^{12}$ Another study indicated a sensitivity of $\sim 90 \%$ and a predictive value $>90 \%$ for the diagnostic precision of FeNO measurements for asthma. ${ }^{13}$

Despite the previously demonstrated contribution of FeNO to the monitoring and diagnosing of asthma in adolescents and young adults, few studies have examined the utility of FeNO measurements in elderly patients. Therefore, our study aimed to assess the contribution of FeNO measurements to the diagnosis of asthma in elderly patients.

\section{Methods}

\section{Epidemiological design and study population}

This study was an observational cross-sectional study that was approved by the Institutional Research Ethics Committee of the Faculty Suprema (number 791.992 of August 26, 2014). It consisted of 202 elderly patients (aged 60 years or older) who visited the Specialty Outpatient Clinic of the Terezinha de Jesus Maternity Hospital of the Faculty of Medicine Suprema at Juiz de Fora, Minas Gerais, Brazil. The exclusion criteria included classes III and IV congestive heart failure, gastroesophageal reflux disease, dementia, Parkinson's disease, sequelae of cerebral vascular accidents, chronic corticosteroid use, immunodeficiency diseases, contraindications of the use of bronchodilators, smokers or former smokers who had stopped smoking $<1$ year previously, and refusal to participate in the study. All of the volunteers who were eligible to participate in the study read and signed the informed consent form that was previously approved by the Institutional Research Ethics Committee of the Faculty Suprema, in agreement with the National Research Council resolution.

\section{Collection procedure and data analysis}

Exclusion criteria were based on clinical history obtained from the patient or patient's family (companion). Specifically, we obtained medical history related to neurological diseases (dementia, Parkinson's disease, or stroke sequelae) that might limit the implementation of procedures. We also analyzed the history of gastroesophageal reflux disease and congestive heart failure that would greatly hinder the differential diagnosis of cough symptoms in this age group. Finally, history of smoking was obtained; smokers and ex-smokers who had quit $<1$ year previously were excluded, since it is known that smoking decreases FeNO values.

All of the clinical symptoms of the elderly patients were assessed with the asthma module of the International Study of Asthma and Allergies in Childhood (ISAAC) test, ${ }^{14}$ which was modified for elderly patients, and the diagnostic routine for COPD, which is based on the Global initiative for chronic Obstructive Lung Disease (GOLD) ${ }^{15}$ In the first step, the elderly patients were diagnosed with probable asthma (PA), definite asthma (DA), COPD, asthma-COPD overlap syndrome (ACOS), or no obstructive pulmonary disease. Among the 202 elderly patients, including all of the groups that were classified in the first stage, 43 were subjected to pulmonary function evaluations (spirometry) and FeNO measurements.

For the diagnosis of asthma, we used the asthma module questionnaire from the original ISAAC, which considers asthma on positive responses to any of the following three questions:

1. Have you ever experienced wheezing in your life (wheezing in your chest)?

2. Have you experienced wheezing in the last 12 months (wheezing in your chest)?

3. Have you ever had asthma or bronchitis in your life?

In this study, we modified this questionnaire in order to consider diagnoses of DA with positive responses to the following questions: 3) Have you ever had asthma or bronchitis in your life? Was the condition confirmed by a doctor? Was PA considered when the response was positive for any of the following two questions? 1) Have you ever experienced wheezing in your life (wheezing in your chest)? or 2) Have you experienced wheezing in the last 12 months (wheezing in your chest)?

For the diagnosis of COPD, chronic respiratory symptoms, which were defined as a cough for 2 months/year for 2 consecutive years and/or persistent dyspnea, were analyzed in patients with smoking habits ( $>20$ packs/year) with the data based on the GOLD criteria for COPD. In contrast, for the diagnosis of ACOS, we selected patients with DA or PA that was associated with COPD, based on the criteria described in the two previously mentioned questionnaires. 


\section{Analysis of ventilation function}

We used a COSMED PonyFx spirometer (COSMED Srl, Rome, Italy) that was connected to a circuit ending in a nozzle. The elderly patients were seated in a chair with their feet flat on the floor, and they were directed to use nose clips and perform maximum inspiratory and expiratory efforts. The following measurements were made: vital capacity, forced vital capacity (FVC), forced expiratory volume in the first second $\left(\mathrm{FEV}_{1}\right), \mathrm{FEV}_{1} / \mathrm{FVC}$, forced expiratory flow between $25 \%$ and $75 \%$ of FVC (FEF $25 \%-75 \%$ ), and maximum forced peak expiratory flow.

\section{Evaluation of the FeNO}

FeNO measurements were performed with an electrochemical analyzer (NIOX MINO; AerocrineAB, Solna, Sweden) according to the protocol described by the American Thoracic Society (ATS) and the European Respiratory Society. ${ }^{16}$ FeNO measurements were conducted while the participants were sitting in front of a computer that contained a visual encourager (installed program) that was used to facilitate the maneuver, which consisted of forced expiration, subsequently closing the lips firmly against the nozzle, performing a deep inspiration, and, finally, performing normal expiration. The greatest value of the two results that did not differ by $>10 \%$ was analyzed (expiratory flow of $50 \mathrm{~L} / \mathrm{s}$ and expiratory pressure at the mouth level of $10 \mathrm{~cm} \mathrm{H}_{2} \mathrm{O}$ ).

Despite the reports that have described reference FeNO values for different populations, the following cutoff points have been recommended by An Official ATS Clinical Practice Guideline: Interpretation of Exhaled Nitric Oxide Levels (FeNO) for Clinical Applications: values $<25$ ppb indicate a low probability for eosinophilic inflammation, values between $25 \mathrm{ppb}$ and $50 \mathrm{ppb}$ are considered intermediary, and values $>50 \mathrm{ppb}$ are considered high. ${ }^{13,17}$

\section{Statistical analysis}

The Mann-Whitney $U$-test was used because the data were not parametric and the low number of individuals was included in the analysis.

\section{Results}

After applying the questionnaires and clinical evaluations for asthma and COPD diagnoses among the 202 elderly patients, 34 were diagnosed with asthma (23 DA and eleven PA), 20 met the COPD criteria, 13 had ACOS, and 135 did not meet the criteria for obstructive pulmonary disease. In terms of age groups, both DA and COPD were the most prevalent conditions in individuals who were 60-69 years old (16\% and $12 \%$, respectively). On performing FeNO in

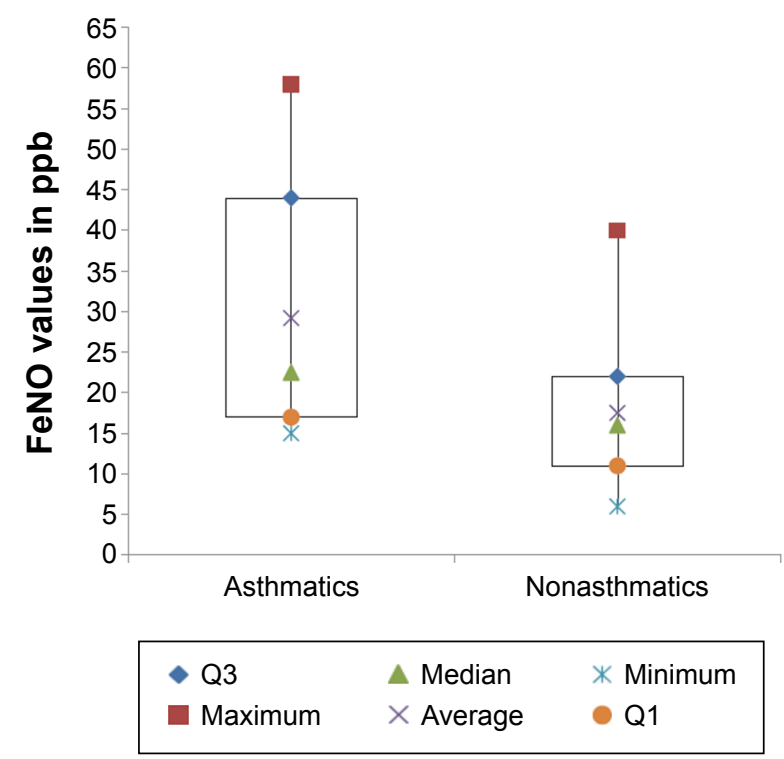

Figure I Comparison of the average values of FeNO between asthmatics and nonasthmatics.

Abbreviations: FeNO, fraction of exhaled nitric oxide; ppb, parts per billion.

the 43 elderly patients who were subjected to spirometry, ten were found to have altered results $(23.2 \%)$ and 33 had normal results $(76.7 \%)$. The average FeNO value of the patients with DA and PA who underwent this procedure was $29.2 \mathrm{ppb}( \pm 4.00 \mathrm{ppb})$, whereas the average FeNO value in the nonasthmatic patients was $17.5 \mathrm{ppb}( \pm 1.53 \mathrm{ppb})$, which was significantly different $(P=0.0002)$. Comparison of median, maximum, and minimum values of $\mathrm{FeNO}$ in elderly patients with PA and DA and without asthma is represented in Figure 1. A comparison of FeNO values between patients with PA and DA is represented in the chart (Figure 2).

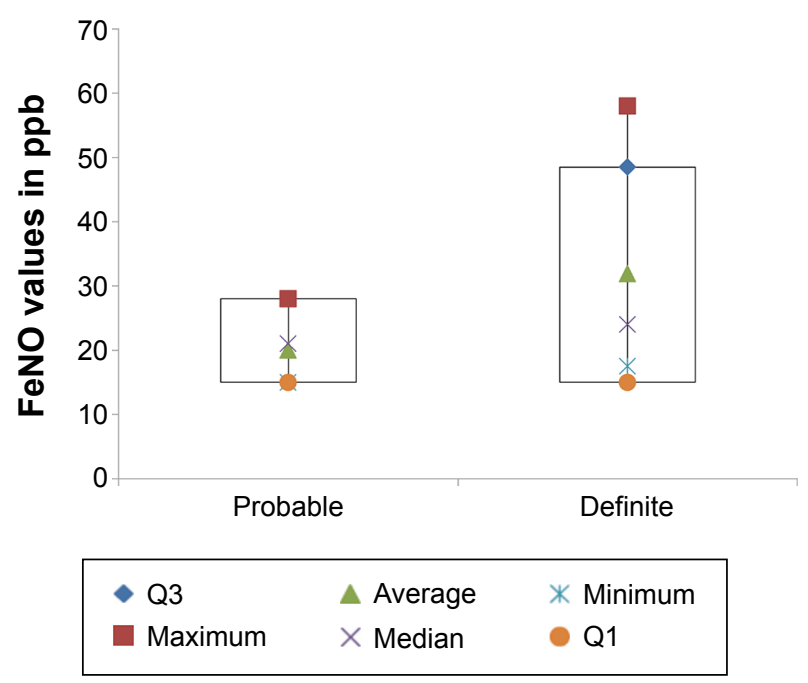

Figure 2 Difference in the average FeNO measurements in the patients with probable asthma (PA) and definitive asthma (DA).

Abbreviations: FeNO, fraction of exhaled nitric oxide; ppb, parts per billion. 


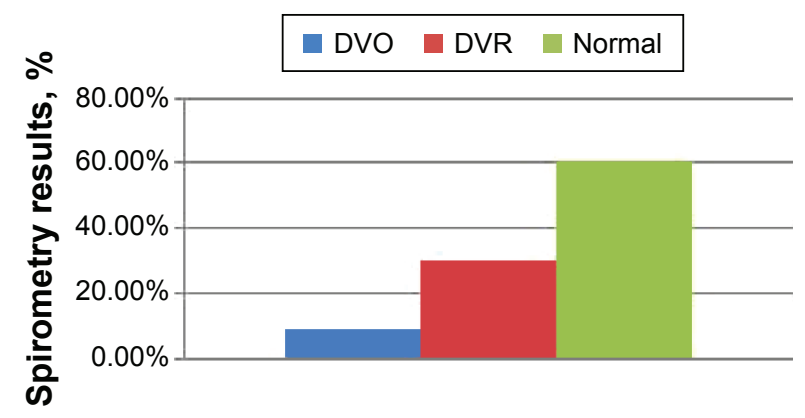

Figure 3 Distribution of the spirometry results of the elderly patients. Abbreviations: DVO, obstructive ventilatory disorder; DVR, restrictive ventilatory disorder.

In the present study, the PA group exhibited FeNO values of $21.0 \pm 3.8 \mathrm{ppb}(\mathrm{n}=3)$, and the DA group exhibited FeNO values of $31.9 \pm 5.5 \mathrm{ppb}(\mathrm{n}=9)$. Thus, the elderly patients with DA showed higher FeNO values $(P=0.4)$ compared with the elderly patients with PA. This difference was not statistically significant, which was probably due to the low number of patients with PA.

Altered FeNO measurements were more prevalent in females $(28.3 \%)$ than in males $(10 \%)$ and in elderly patients between 60 years and 69 years old $(31.2 \%)$.

The spirometry results showed that, among the 43 elderly patients, four had a diagnosis of obstructive ventilatory disor$\operatorname{der}(9.3 \%), 13$ had a restrictive ventilatory disorder (30.2\%), and 26 did not have any alterations in their spirometry results (60.4\%; Figure 3).

Twelve patients with DA and PA who were diagnosed using the asthma module of the ISAAC questionnaire that had been modified for the elderly patients underwent spirometry, and none presented with obstructive ventilatory disorder. In contrast, when six elderly patients who were diagnosed with ACOS in the first part of the study performed spirometry, one presented with obstructive ventilatory disorder and had a negative result on the bronchodilator test. Table 1 shows that there was no relationship between the FeNO values and the tests for pulmonary function in our sample.
Among the 20 patients who were diagnosed with COPD using clinical criteria (GOLD study), 12 were subjected to spirometry, and three (25\%) had their diagnoses confirmed. Males had a higher prevalence of altered spirometry results than did females (50\% and $36.3 \%$, respectively). In addition, the age group with the highest prevalence of altered spirometry results was the 80 years or older group, in which $60 \%$ of the elderly patients showed alterations (restrictive ventilatory disorder).

\section{Discussion}

Asthma is underdiagnosed in elderly patients because of the atypical symptoms, which are also associated with aging, and the decreased perception of their respiratory symptoms by the patients themselves, which are frequently due to aging itself or due to other diseases that are common comorbidities in the elders. ${ }^{8}$ Symptoms of wheezing, dyspnea, and sleep disturbance are nonspecific in elderly patients, and elderly patients with these symptoms have been considered in the literature as individuals with PA. However, the medical diagnosis of asthma is more specific, as it is associated with a history of medical visits and previous medical follow-up events that are more common in this age group. In these cases, studies usually classify these elderly patients with DA. ${ }^{18-22}$ Therefore, we decided to use the asthma module of the ISAAC questionnaire with some modifications in order to diagnose asthma during the first part of our study.

In this study, the FeNO results of the 43 assessed elderly patients showed a clear relationship between the respiratory symptoms that are commonly attributed to asthma (mainly wheezing) and previous medical diagnoses that were reported by patients on the elderly modified ISAAC questionnaire. In the first part of the study, patients with asthma diagnoses (DA and PA) exhibited FeNO values $(29.2 \pm 4.00 \mathrm{ppb})$ that were considerably higher than those of the nonasthmatic patients $(17.5 \pm 1.53 \mathrm{ppb})$. Figure 1 shows the absence of outliers, so that the median value is a reliable parameter

Table I Correlation matrix demonstrating no association between the fraction of exhaled nitric oxide (FeNO) and the spirometric variables

\begin{tabular}{|c|c|c|c|c|c|c|c|c|c|c|c|}
\hline & \multicolumn{11}{|c|}{ FeNO } \\
\hline & FVC & FEV & PEF & PIF & FEV $_{1} /$ FVC $\%$ & FEF25\%-75\% & MEF75\% & MEF50\% & MEF25\% & FETI00\% & PEF \\
\hline$r$ & -0.19 & -0.15 & -0.14 & -0.16 & 0.03 & -0.13 & -0.12 & -0.15 & -0.13 & -0.09 & -0.14 \\
\hline$r^{2}$ & 0.03 & 0.02 & 0.02 & 0.02 & 0.00 & 0.02 & 0.01 & 0.02 & 0.02 & 0.01 & 0.02 \\
\hline$P$-value & 0.23 & 0.34 & 0.37 & 0.35 & 0.85 & 0.42 & 0.44 & 0.32 & 0.39 & 0.59 & 0.37 \\
\hline
\end{tabular}

Note: FEV,/FVC: Tiffeneau index.

Abbreviations: FEF $25 \%-75 \%$, forced expiratory flow between $25 \%$ and $75 \%$ of FVC; FET, forced expiratory time; FEV , forced expiratory volume in one second; FVC, forced vital capacity; MEF, mid expiratory flow; PEF, peak expiratory flow; PIF, peak inspiratory flow; $r$, correlation coefficient; $r^{2}$, coefficient of determination. 
for demonstrating the difference between these groups of elderly individuals.

The 2011 ATS described cutoff values of FeNO measurements. Values $<25 \mathrm{ppb}$ indicated a low probability of eosinophilic inflammation and response capacity to steroids. In contrast, FeNO values $>50 \mathrm{ppb}$ strongly suggested eosinophilic inflammation and a response to steroid treatment. ${ }^{17}$ However, several studies have shown the benefits of treatment with corticoids in patients with FeNO values between $25 \mathrm{ppb}$ and $50 \mathrm{ppb}$, despite these values being considered intermediary. ${ }^{23-27}$ Sato et al described that a cutoff value of $38.8 \mathrm{ppb}$ had a sensitivity of $79.2 \%$ and a specificity of $91.3 \%$ for asthma diagnosis. ${ }^{12}$ Smith et al used a cutoff value of $20 \mathrm{ppb}$ in their study, with a sensitivity of $88 \%$ and a specificity of $79 \%$ for asthma diagnosis. ${ }^{28}$ In a recent study that used the same methodology as previous investigations, a sensitivity of $72 \%$ and a specificity of $74.8 \%$ were observed with a cutoff value of $41 \mathrm{ppb} .{ }^{29}$ Thus, in studies performed to date, the cutoff values of FeNO for asthma diagnoses were below $50 \mathrm{ppb}$, and all had a specificity exceeding $70 \%$. Therefore, in our study, the average FeNO values in the asthmatic patients were in agreement with these previous studies.

The results of our study did not correlate with those of Columbo et al. ${ }^{23}$ The FeNO values did not increase in the patients' follow-up examinations, which were performed every 3 months. However, the elderly patients who were selected for their study were all stable and under treatment with inhaled corticoids, ${ }^{24}$ whereas one of the exclusion criteria in this study was treatment with corticoids. Other investigations have shown the influence of corticoids in decreasing FeNO values, and this may have influenced the finding of an absence of a relationship between the elderly asthmatic patients and the FeNO values. ${ }^{24}$

Other factors that have a significant effect on FeNO measurements are smoking (decreases values), infection with rhinoviruses (increases values), and ingestion of green leafy vegetables (increases values). In our study, we excluded smokers and former smokers who had stopped smoking for $<1$ year. We were also careful about conducting the tests during the morning and at least 1 hour after the patients had ingested food. In patients who presented symptoms of the common cold, the test was rescheduled for 2 weeks later as was recommended in the study that was published by Bjermer et al. ${ }^{24}$

In terms of age, our study showed a higher proportion of altered FeNO measurements in younger elderly individuals (60-69 years old) than in the older patients ( $70-79$ years old and 80 years old or older). In a recent study of 3,081 patients between 6 years and 80 years of age without pulmonary disease who underwent FeNO evaluations, increases in FeNO measurements were observed in 6-14-year-old girls and 6-16-year-old boys, with a plateau occurring until 45-59 years of age in women and men, respectively, with a further increase with age for both sexes until 80 years of age. ${ }^{10}$ That study excluded patients with previous asthma or COPD diagnoses and patients with systemic inflammatory processes due to eosinophilia and altered $\mathrm{C}$-reactive protein; thus, the FeNO measurements were conducted only in individuals without any evident inflammatory processes. In addition, despite the large number of individuals included in the study, it did not differentiate the elderly patients by their age group, but considered all patients, including females from 45 years to 80 years old and males from 59 years to 80 years old, as a group, as the aim of the study was not to assess FeNO in the elderly patients but rather its evolution during all stages of life.

In the present study, ten elderly patients showed altered FeNO values $(>25 \mathrm{ppb})$, which indicated a Th2-type inflammatory process and which suggested asthma. Table 1 (correlation matrix) shows that no spirometric variable was significantly correlated with FeNO values; such a relationship would be identified by Pearson's correlation coefficient ( $r$ ) of -1 , since the expected relationship between lung function and FeNO values is negative. As an example, we highlight $\mathrm{FEV}_{1}$, with $r=-0.15$ and $P=0.34$, which supports the lack of correlation. Similarly, the $\mathrm{FEV}_{1} / \mathrm{FVC}$ ratio showed $r=0.03(P=0.85)$. Thus, the dosage of FeNO is a supplementary procedure and is not a substitute for spirometry. Columbo et $\mathrm{al}^{23}$ assessed the correlations between FeNO measurement and spirometry results. In their study of 30 asthmatic patients, no significant correlations were reported between $\mathrm{FeNO}$ and $\mathrm{FEV}_{1} / \mathrm{FVC}$ or other spirometry values. $^{24}$

In addition, using spirometry, we identified four elderly patients with obstructive ventilatory disease, none of whom presented altered FeNO values. The inflammatory processes in the airways in patients with COPD are mediated by Th1 cells, with a predominance of neutrophils and low numbers of eosinophils, which would not be reflected by FeNO measurements. ${ }^{27}$ FeNO measurements may be most useful in patients with COPD to identify patients with ACOS, which is very common in the elderly patients. ${ }^{19}$ In our study, we found 13 patients who fit the criteria for ACOS; six of these underwent FeNO measurements, and two (33.3\%) were found to have altered values. Due to the small number 
of patients with this condition, we were limited in analyzing the possible correlations between FeNO and this group of elderly patients.

The spirometry method showed limitations in the diagnosis of obstructive ventilatory disorder in this age group. Learning ability and skill, which are commonly altered in the elders, are essential to perform spirometry adequately. Moreover, another particularity of spirometry in the elders is the decline in pulmonary function from the fourth decade, so that $\mathrm{FEV}_{1}$ is reduced by nearly $30 \mathrm{~mL} /$ year. After 70 years of age, there is a reduction of $60 \mathrm{~mL} /$ year. Therefore, the $\mathrm{FEV}_{1} / \mathrm{FVC}$ values in the elderly patients older than 65 years of age should be $64 \%$ and in those older than 85 years of age should be $56 \%$. A $70 \% \mathrm{FEV}_{1} / \mathrm{FVC}$ value in elderly patients would result in excessive diagnoses of obstructive respiratory diseases. ${ }^{8}$

Importantly, this study may have some limitations due to the small number of patients included; further studies with a larger number of elderly individuals are required to confirm our findings. The present study showed a significant correlation between FeNO values and a previous history or typical symptoms of asthma in the elderly patients. The same relationship was not observed in the evaluations of pulmonary function, as none of the patients who were identified with DA or PA in the first stage of the study showed alterations in spirometry that would suggest the presence of asthma. Therefore, our study indicates that measurements of FeNO may contribute to asthma diagnoses in elderly patients, which would result in the benefits of earlier and more efficient treatment.

\section{Acknowledgments}

The present study was supported by Rede Mineira de Bioterismo (31/11) e Rede Mineira de Toxicologia (26/11)FAPEMIG - Fundação de Amparo à Pesquisa de Minas Gerais.

\section{Author contributions}

All authors contributed toward data analysis, drafting and revising the paper and agree to be accountable for all aspects of the work.

\section{Disclosure}

The authors report no conflicts of interest in this work.

\section{References}

1. Han MK, Muellerova H, Curran-Everett E, et al. GOLD 2011 disease severity classification in COPD Gene: a prospective cohort study. Lancet Respir Med. 2013;1:43-50.
2. Global Initiative for Asthma-GINA. [webpage on the Internet]. Global Strategy for Asthma Management and Prevention. Bethesda: Global Initiative for Asthma. Available from: http://www.ginasthma.org/. Accessed December 12, 2015.

3. Tattersfield AE, Knox AJ, Britton JR, Hall IP. Asthma. Lancet. 2002; 360:1313-1322.

4. Künzli N, Stutz EZ, Perru Choud AP, et al. Peak flow variability in the SAPALDIA study and its validity in screening for asthma-related conditions. The SPALDIA Team. Am J Respir Crit Care Med. 1999; 160:427-434.

5. Osborne ML, Pedula KL, O'Hollaren M, et al. Assessing future need for acute care in adult asthmatics: the profile of Asthma Risk Study: a prospective health maintenance organization-based study. Chest. 2007;132:1151-1161.

6. Crapo RO, Casaburi R, Coates AL, et al. Guidelines for methacholine and exercise challenge testing-1999. This official statement of the American Thoracic Society was adopted by the ATS Board of Directors, July 1999. Am J Respir Crit Care Med. 2000;161:309-329.

7. Hunter CJ, Brightling CE, Woltmann G, Wardlaw AJ, Pavord ID. A comparison of the validity of different diagnostic tests in adults with asthma. Chest. 2002;121:1051-1057.

8. Yáñez A, Cho SH, Soriano JB, et al. Asthma in the elderly: what we know and what we have yet to know. World Allergy Organ J. 2014;7:8.

9. Donohue JF, Herje N, Crater G, Rickard K. Characterization of airway inflammation in patients with COPD using fractional exhaled nitric oxide levels: a pilot study. Int J Chron Obstruct Pulmon Dis. 2014;9: 745-751.

10. Jacinto T, Malinovschi A, Janson C, Fonseca J, Alving K. Evolution of exhaled nitric oxide levels throughout development and aging of healthy humans. J Breath Res. 2015;9:036005.

11. Garthwaite J. Nitric oxide signaling in the nervous system. Semin Neurosci. 1993;5:171-180.

12. Sato S, Saito J, Sato Y, et al. Clinical usefulness of fractional exhaled nitric oxide for diagnosing prolonged cough. Respir Med. 2008;102: 1452-1459.

13. Munakata M. Exhaled nitric oxide (FeNO) as a non-invasive marker of airway inflammation. Allergol Int. 2012;61:365-372.

14. Solé D, Naspitz C. Epidemiologia da asma: Estudo ISAAC [International Study of Asthma and Allergies in Childhood]. Rev Bras AlergiaImunopatol. 1998;21:38-45.

15. American Thoracic Society; European Respiratory Society. ATS/ERS recommendations for standardized procedures for the online and offline measurement of exhaled lower respiratory nitric oxide and nasal nitric oxide, 2005. Am J Respir Crit Care Med. 2005;171(8):912-930.

16. Dweik RA, Boggs PB, Erzurum SC, et al. An official ATS clinical practice guideline: interpretation of exhaled nitric oxide levels (FENO) for clinical applications. Am J Respir Crit Care Med. 2011;184: 602-615.

17. Bauer BA, Reed CE, Yunginger JW, Wollan PC, Silverstein MD. Incidence and outcomes of asthma in the elderly. A population-based study in Rochester, Minnesota. Chest. 1997;111:303-310.

18. Kitaguchi Y, Komatsu Y, Fujimoto K, Hanaoka M, Kubo K. Sputum eosinophilia can predict responsiveness to inhaled corticosteroid treatment in patients with overlap syndrome of COPD and asthma. Int J Chron Obstruct Pulmon Dis. 2010;7:283-289.

19. Hanania NA, King MJ, Braman SS, et al. Asthma in the elderly: current understanding and future research needs - a report of a National Institute on Aging (NIA) workshop. J Allergy Clin Immunol. 2011;128: S4-S24.

20. Marincu I, Frent S, Tomescu MC, Mihaicuta S. Rates and predictors of uncontrolled bronchial asthma in elderly patients from western Romania. Clin Interv Aging. 2010;10:963-967.

21. Stupka E, deShazo R. Asthma in seniors: Part 1. Evidence for under diagnosis, under treatment, and increasing morbidity and mortality. Am J Med. 2009;122:6-11.

22. Sverrild A, Malinovschi A, Porsbjerg C, Backer V, Alving K. Predicting airway hyperreactivity to mannitol using exhaled nitric oxide in an unselected sample of adolescents and young adults. Respir Med. 2013; 107:150-152. 
23. Columbo M, Wong B, Panettieri RA Jr, Rohr AS. Asthma in the elderly: the role of exhaled nitric oxide measurements. Respir Med. 2013; 107:785-787.

24. Bjermer L, Alving K, Diamant Z, et al. Current evidence and future research needs for FeNO measurement in respiratory diseases. Respir Med. 2014;108:830-841.

25. Malinovschi A, Van Muylem A, Michils A. Both intermediate and high exhaled nitric oxide levels predict improvement in asthma control after new-onset of inhaled corticosteroids. Eur Ann Allergy Clin Immunol. 2013;68:164.

26. Rouhos A, Kainu A, Piirilä P, et al. Repeatability of exhaled nitric oxide measurements in patients with COPD. Clin Physiol Funct Imaging. 2011;31:26-31.
27. Wang Y, Li L, Han R, et al. Diagnostic value and influencing factors of fractional exhaled nitric oxide in suspected asthma patients. Int J Clin Exp Pathol. 2015;8:5570-5576.

28. Smith AD, Cowan JO, Filsell S, et al. Diagnosing asthma: comparisons between exhaled nitric oxide measurements and conventional tests. Am J Respir Crit Care Med. 2004;169:473-478.

29. Bellia V, Pistelli R, Catalano F, et al. Quality control of spirometry in the elderly. The SA.R.A. Study. Salute Respiration nell' Anziano (Respiratory Health in the Elderly). Am J Respir Crit Care Med. 2000;161: 1094-1100.
Clinical Interventions in Aging

\section{Publish your work in this journal}

Clinical Interventions in Aging is an international, peer-reviewed journal focusing on evidence-based reports on the value or lack thereof of treatments intended to prevent or delay the onset of maladaptive correlates of aging in human beings. This journal is indexed on PubMed Central, MedLine,

\section{Dovepress}

CAS, Scopus and the Elsevier Bibliographic databases. The manuscript management system is completely online and includes a very quick and fair peer-review system, which is all easy to use. Visit http://www.dovepress. com/testimonials.php to read real quotes from published authors. 